\title{
Cultural Perspectives in the Economic Development of African Regional Integration: The Case of the Economic and Monetary Community of Central Africa (EMCCA)
}

\author{
Lédaga Néhémie Sabrina, Wei Hong, Mfoubou Elvis Presley \\ Central China Normal University (CCNU), Department of Politics and International Studies, Wuhan, China \\ Email: nledaga@yahoo.fr,weihong802@163.com, elvispresleymfoubou@gmail.com
}

How to cite this paper: Sabrina, L. N., Hong, W., \& Presley, M. E. (2020). Cultural Perspectives in the Economic Development of African Regional Integration: The Case of the Economic and Monetary Community of Central Africa (EMCCA). Open Journal of Political Science, 10, 329-346. https://doi.org/10.4236/ojps.2020.102021

Received: April 6, 2020

Accepted: April 27, 2020

Published: April 30, 2020

Copyright $\odot 2020$ by author(s) and Scientific Research Publishing Inc. This work is licensed under the Creative Commons Attribution International License (CC BY 4.0).

http://creativecommons.org/licenses/by/4.0/

\begin{abstract}
When we are talking about the globalization of trade and the regionalization of economic forces, it seems necessary, for Africa and for the member countries of the Economic and Monetary Community of Central Africa (EMCCA) in particular to think about new strategies for reviving their economies prone to many challenges. The cultural field via cultural tourism and cultural industries appears here, as one of the best assets to respond to the current international, regional and national challenges from which these countries suffer in trade. Thus, much more than highlighting the difficulties they face, this article aims to show the importance of culture in the economic development of African regional integrations and the Economic and Monetary Community of Central Africa in singularity. Documentary and qualitative research methods have served as a basis throughout this work.
\end{abstract}

\section{Keywords}

Cultural Impact, Regional Integration, Economic Development, EMCCA, Challenges, Prospects

\section{Background}

\section{- The genesis of the EMCCA}

The question of integration has always raised many research questions because it contains several forms of nuance. We are talking about political, military, economic, social, cultural, professional integration and so on. However, concerning this article, we have focused only on the intra-regional economic in- 
tegration of the member countries of the Economic and Monetary Community of Central Africa (EMCCA). It should be remembered that the need to weave and consolidate ties of economic solidarity in Central Africa was initiated long before independence. In fact, in 1959, there was already the Equatorial Customs Union (ECU), which brought together the Central African Republic, the Congo, Chad, and then Cameroon, which integrated it in 1962. The other states, which had also become independent, decided to join it and set up, the first Central African integration organization called the Customs and Economic Union of Central Africa (CEUCA). Its objective was to gradually establish a common market between the member states; remove obstacles to the development of intra-Community trade to promote the extension of national markets and improve the standard of living of the populations; strengthen the unity of the economies involved and modernize them to ensure their regular development (...) by harmonizing industrialization policies, equitable distribution of community projects and coordinating development programs for different production sectors (Edouard, 2004). It was the Treaty of Brazzaville, dating from December 1964 that instituted it, but the latter did not come into force until January 1966. This slowness can be explained because the latter should create a real customs union (with a common fund of solidarity) and not just a free trade area; but also organized economic cooperation, especially in terms of setting up industries; its application could only be progressive, and it seemed to be on the right track (François, 1968). However, structural, political difficulties, the economic crisis of 1990, and so on, did not take long to arise and despite the efforts made and the internal restructuring put in place, the latter failed to achieve the objectives set for it were assigned. It was, therefore, necessary, urgently to create a new institution of regional economic integration, deemed more modern and more concerned with new inter-regional ambitions in the face of the challenges that aroused economic regionalization and the globalization of trade. It is with this in mind that the CEUCA will disappear to make way for the Economic and Monetary Community of Central Africa (EMCCA).

The Economic and Monetary Community of Central Africa was created in 1994, but the treaty establishing it did not come into force until 1999. Formally made up of six border countries: Gabon, Equatorial Guinea, the Central African Republic, the Republic of Congo, Cameroon, and Chad, these countries all have in common, except for Equatorial Guinea colonized by Spain: France as a former colonizer and the use of CFA Francs as currency. Also, since 2013, its headquarters have been temporarily located in Malabo (Equatorial Guinea) for security reasons. It must be said that from the Customs and Economic Union of Central Africa (CEUCA) to the Economic and Monetary Community of Central Africa (EMCCA), thirty-five years have passed and of the Economic and Monetary Community of Central Africa to the present day, twenty-one years have passed, making a total of fifty-six years of existence. It is about the same lifespan of African independence up to the present day. In 56 years of reforms, internal restructuring, and multiple political changes, this organization remains considered 
by some analysts as a "failure of integration". To qualify it, terms such as "least advanced", "least integrated", "least diverse" even "least connected" from the African continent are used. All these low-value names highlight the plurality of difficulties encountered by the Economic and Monetary Community of Central Africa in trade. However, one of these objectives is to make this region an integrated, emerging economic space, where solidarity and good governance reign by 2025 . This initiative could have worked if we did not have the world's oil crisis. The experts said that the price of Brent decreased from USD 110 to USD 35 per barrel between 2014 and 2016. This drop caused several troubles to oil producer and consumer countries in economic and geopolitical fields (Niambi, 2018).

\section{- The importance of the oil for EMCCA members}

Since its establishment, EMCCA has so far registered very few satisfactory results in terms of inter-regional economic exchanges. However, it must be recognized for the improvement in these economic performances over the years 2016 to 2019, closely linked to oil exports, which occupy a central place in the economies of the member countries as shown in Table 1 below. Indeed, being oilproducing and exporting countries, these six countries are very dependent on this mineral resource, which is the main income of their economies.

The table below shows the importance of oil production and the exploitation of these states. On average in recent years, EMCCA has produced 45 million tons of oil. Likewise, on average, the share of oil GDP in overall GDP is around $20 \%$; that of oil exports in total exports is $65 \%$ and that of oil revenues in total budget revenue $38 \%$ (CEMAC, 2019). Besides, it must be said that several countries in the zone export almost only their oil production. In 2006, it represented 91\% of exports from Equatorial Guinea, 84\% of those from Chad, 83\% from Gabon, $82 \%$ from Congo and 48\% from Cameroon (Emilie \& Serge, 2014). Except for Cameroon, whose oil production is limited, the wider domestic market and the economy more diversified, the countries of the sub-region are extremely dependent on oil revenues, the consequences of poor diversification of the economy. If oil contributes less than $10 \%$ of Cameroon's GDP, this rate rises to 85\% for Equatorial Guinea, around 50\% for Congo-Brazzaville and barely less (45\%) for Gabon (Direction générale des relations internationales et de la stratégie, 2015). However, despite the importance of this sector of activity for EMCCA, it must be said that its return in intra-community trade remains overall very low

Table 1. Importance of oil in EMCCA economies.

\begin{tabular}{ccccc}
\hline & 2015 & 2016 & 2017 & 2018 \\
\hline Production in millions of tons & 47.7 & 44.3 & 42 & 44.2 \\
Share of oil GDP in total GDP & $23.8 \%$ & $18 \%$ & $18.4 \%$ & $20.4 \%$ \\
Share of oil exports in total exports & $61.9 \%$ & $66.2 \%$ & $68.9 \%$ & $66.5 \%$ \\
Share of oil revenues in budgetary revenues & $40.5 \%$ & $31.1 \%$ & $36 \%$ & $42.3 \%$ \\
\hline
\end{tabular}

Source: CEMAC, 2019. 
and unenviable. Also, in EMCCA, the majority of its populations living in deplorable conditions and immense poverty. However, this region of Central Africa is full of multiple resources and potentials, including the cultural domain. Hence our interest in this research subject because it is essential to update the debates and to see to what extent the Economic and Monetary Community of Central Africa would benefit from having better visibility both on the African and international scene and would favor at the same time good economic profitability for member countries and these populations. Moreover, to achieve this, all economic fields, even that of culture must be collectively explored. The interest in exploring the cultural domain as a solution is desirable and essential. Not to dissociate the economy from culture but rather in a complementary way because one cannot function well without the other, because culture can help hasten and consolidate the processes of restructuring economic spaces. On the other hand, cultural action itself can only develop if it rests on solid material and economic base. It cannot be disconnected from the socio-economic reality, which constitutes its framework (Plan d'action sur les industries culturelles et creatives, 2004). As the cultural field is an important sector for the economic development of African regional integrations, regional integration is a solid and essential basis for the development of African cultural enterprises in general and that of EMCCA in particular. It is, therefore, necessary to know, in what way does the cultural field via cultural tourism and the cultural industries constitute a nonnegligible prospect for economic development in EMCCA? How is regional integration an asset for the economic development of this sector?

A logical follow-up to this work will be, firstly to present the literature, which allowed us to develop this work; then list some of the difficulties encountered by the EMCCA before showing the importance of culture on EMCCA's economic development. Obviously, the aim of this article is not to fall into a demeaning criticism of these countries and their integration organization, but rather to make a modest contribution to the list of scientific, literary research, and economical already available. More than presenting the shortcomings within the EMCCA, we will pay particular attention to the cultural field which so far remains an individual prerogative little rewarding and neglected.

\section{Literature Review}

From the 1960s to the present day, numerous analyzes, political and economic studies on the subject of regional integration have emerged. However, we believe that the emphasis on the cultural field is recent and deserves closer attention. This renewed interest in contemporary and few are the manuscripts or other articles, which have raised the question on the impact of the cultural field and the importance of regional economic integration as factors of development. Moreover, given the challenges that EMCCA countries continue to face, all areas must be explored and exploited. We count to date, few sources related to our research but our review of the literature comes for most of the authors from the African continent. This attests to the importance of the question of regionalism in Africa 
to give it a new boost of hope and optimism. Thus, we have researchers from one part of West Africa: Francisco Ayi of Almeida, Nagou Madow, Cheick Oumar Sissoko, Jacqueline Damon; on the other hand, from Central Africa Nouwoue Njofang D., Kanel Engandja-Ngoulou, and international contribution.

For Francisco Ayi of Almeida, only regional integration can promote the growth of African economies. Indeed, it supports the fact that the development of African cultural industries could be articulated in the audio-visual sectors (music, image, live performance), everyday objects and writing necessary for the development of human capital and the expression of identities. They have the advantage of having high demand linked to high expectations from the public and have a high capacity for integration. Only an economic space like the regional space is conducive to consolidating and developing their capacity to meet demand (Francisco, 2006). He gives four main reasons in his article to support his remarks. First, to prioritize his case, he alludes to the narrowness of national markets, technical under-equipment, insufficient basic infrastructure, weak purchasing power and the loss of importance of national borders. Secondly, he affirms that taken sector-by-sector, African cultural industries do not have sufficient production and they will not be able to respond effectively to the constraints of competitiveness imposed by the international market. Third, it attests that the scale of investment in technical infrastructure, vocational training, and financial support exceeds the capacity of each country. Finally, he asserts that most of these cultural industries are already oriented towards the domestic markets and their products rarely manage to be placed on the international markets. In short, $\mathrm{M}$. Almeida fiercely supports the idea that intra-regional cooperation is a priority strategic objective to be taken into account, proceeding in stages going from sub-regional to regional and then to inter-regional.

Following the same logic as his predecessor, Mrs. Jacqueline Damon affirms that parallel to the process of globalization, regional integration is becoming more than ever a critical element for the development of Central Africa. The regional question is geopolitical and refers to economic, political and cultural interdependencies. The future of the region depends in particular on its ability to create or renew bonds of trust between populations, institutions and key organizations through regional dynamics and concrete cross-border actions, a prerequisite for regional stability (Jacqueline, 2005). It further argues that regional integration is at the heart of development in Africa and that a careful study should be conducted to show how environmental, demographic, economic and cultural factors could, beyond political news, favor integration, or on the contrary, hinder it.

From a similar point of view, Dr. Nagou Madow Yves defends the idea that cultural diversity is an asset for regional integration. Indeed, he asserts that for the cultural factor to play an accelerating role in the process of regional integration; the necessary and sufficient conditions must be defined for the establishment of a legal order in which political and social interactions must be able to be articulated while respecting the principle of equality (Nagou, 2012). And ac- 
cording to Professor Nouréini quoted in the same article, for African integration to succeed, it must necessarily go through the integration of minds so that the education-culture interface becomes a reality on the continent, thus, the term "community" used will it reflect reality only if, at a first level, the children can have the same school program at the elementary level, that they learn the same values and pass by the same textbooks and when they grow, they will already be integrated from West Africa without necessarily talking about politics and economics since the shared values will be the same (Nagou, 2012).

On the Central African side, we have as a reference model the Dr. in law and political science of Jean Moulin University, Kanel Engandja-Ngoulou. It is from his expertise that our research subject took shape. In his book titled The Development of Cultural Industries in Gabon, he gives a panoramic and specific view of how this small country that is Gabon with less than two million inhabitants, could make its way through the cultural industries for him provide economic visibility on the international scene and in turn in intra-regional trade. Its analysis not only helps Gabon to redefine its objectives in terms of cultural policies in the face of cultural industries but also helps by extension its French-speaking neighbors to think more communally than individually for better growth of the economies in Central Africa. Mr. Kanel affirms that seizing culture, more specifically cultural industries to found its development is one of the possibilities that Africa must explore to benefit from the positive spinoffs of globalization (Kanel, 2012). Moreover, he bases his arguments by focusing on the field of publishing, the music industry and that of the audiovisual sector, namely radio, television, and cinema.

Finally, we cannot omit international opinion particularly that of the African Union in the action plan on the cultural and creative industries. According to their expertise, culture can help bring together what politics have separated. It can also help hasten and consolidate the processes of restructuring economic spaces. On the other hand, cultural action itself can only develop if it rests on solid material and economic base. It cannot be disconnected from the socioeconomic reality, which constitutes its framework.

Here enumerate, the authors concerning the review of the literature of our work. Although these authors have dealt with questions related to our theme, the scientific literature is not yet abundant. However, their work already allows us to appreciate and have precise ideas on the subject. Thus, to better understand all the aspects related to our research questions, we will continue by showing the economic challenges of EMCCA including the origins, then, we will end by showing the importance of the cultural field in the economic development of regional integrations African and EMCCA singularity.

\section{Some Economic Challenges within the EMCCA}

In his thesis published in 2010, entitled the Free movement of people within the EMCCA space. between myths and realities, Serge Loungou, affirms that EMCCA is 
not strictly speaking a free trade area or a union custom, much less a common market, following the stages of regional economic integration theory. This is where the whole paradox of decisions taken unanimously, but in essence, testifies to the lack of volunteerism of EMCCA political leaders. Similarly, according to the affirmation of the Circle of Reflection and Orientation on the Sustainability of the Chadian Economy, intra-regional trade in the EMCCA zone remains constantly low, going from $1.6 \%$ for exports and $3.1 \%$ for imports in 2013. Suffice to say that in EMCCA, the difficulties are numerous and affect several sectors of activity. Among them are:

\section{- The challenges related to the Oil sector}

The EMCCA countries are oil-producing and exporting nations. This mineral resource is the main source of their savings. And For such economies, the slightest fall in the price of a barrel of oil (as was the case between 2014-2016), is a real difficulty which sometimes even goes so far as to paralyze the functioning of the state and the financial management of states. It must be said that when the growth of the economies of the States, in particular, those of the Economic and Monetary Community of Central Africa depend only on the fluctuation of oil prices whose forecast is sometimes uncertain as to the only source of income, the economic decline is more than a certainty while knowing that oil is not a renewable resource at the rate of our consumption. Oil, which accounts for $60 \%$ of EMCCA's exports, experienced a collapse in its prices, which resulted in the halving of oil revenues between 2014 and 2016. The deficit in the region's current account widened thus markedly widened, from $3.9 \%$ of the gross domestic product in 2014 to $9.3 \%$ of GDP in 2016. Public debt increased from 29\% of GDP in 2014 to $47 \%$ of GDP in 2016 (CEMAC, 2019). Since the fall in oil prices and its consequences on demand, the deterioration of the security climate in the Lake Chad region and in CAR which adds to structural weaknesses, notably the lack of diversification of economies and a level of weak institutional governance, all of which are behind the poor economic performance which translates into a substantial reduction in economic growth in the region. The growth rate of the zone thus passed from $4.8 \%$ in 2014 to $1.4 \%$ in 2015 and $-0.2 \%$ in 2016 (...). These poor performances also led to a deficit of current transactions in the zone which passed from $4.1 \%$ of GDP in 2014 to $12.5 \%$ in 2015 , due to a large decline in the trade surplus, with a drop of more than $30 \%$ in the product of oil exports, but also a slight worsening of the deficit in the balance of services (CEMAC, 2019).

Besides, the majority of their economies remain weak because they are not very diversified. Several countries of the zone, export almost only their oil production except for Cameroon, which has the most diversified economy in EMCCA. The latter remains one of the main world producers of certain food products, such as cocoa, coffee, bananas, palm products, tobacco, rubber, cotton, corn, and cassava, according to the Chartered Accountants in 2020. Given these realities, the economic climate in the EMCCA zone remains very difficult since there are not many quality products to trade between them. 


\section{- The challenges related to the constructor sector}

From North to South, East to West, African cities are metamorphosed. We have just seen that the oil sector is closely linked to the building and the public works essor (Niambi, 2019). In the EMCCA zone, as in the majority of African countries, the infrastructure problem is very obvious. The reality is still incomprehensible when it comes to oil-producing and exporting countries. The emergence of 2025 appears more difficult to materialize knowing that the highways connecting the different metropolises are not very viable or even impassable for others. In 2010, EMCCA had set up the Regional Economic Program (PER), broken down into 5 axes, 12 strategic objectives, 29 programs and 86 projects. The objective of this program was to make EMCCA an integrated economic space (...) at the service of human development by 2025. However, almost 10 years after its launch and approximately 5 years before the deadline, less than $20 \%$ of the Program has been completed (Geslin, 2019). Furthermore, according to the expertise made by the United Nations in their report entitled Africa Renewal published in 2014, the limited implementation of the agreements and the lack of reliable infrastructure complicate the pursuit of regional integration. The main road network of EMCCA is $57,858 \mathrm{~km}$ long, of which only $12 \%$ is paved, and its road density for the entire network is $1.9 \mathrm{~km} / 100 \mathrm{~km}$, including 0.24 $\mathrm{km} / 100 \mathrm{~km}$ for paved roads. Unlike other regional communities, we observe that almost the entire EMCCA road network is not in good condition (Etienne, 2012). Road transport is incredibly slow and ports are congested due to lack of capacity. Indeed, the lack of an adequate road network is one of the main causes of the non-competitiveness of products from different EMCCA countries, in terms of cost, quality, quantity, delivery times, etc. For example, road harassment induces a cost representing $52 \%$ of the value of exports on the route from Douala (Cameroon) to N'Djamena (Chad), $1864.6 \mathrm{~km}$ long, for an average duration of 15 days, to which must be added up to 28 additional days of waiting time in the port of Douala. Thus, more than $15 \%$ of agricultural production is lost between the place of production and consumption and bad sales are recorded due to inadequate transport infrastructure and numerous checkpoints, reducing the turnover of producers and, consequently a drop in production and an increase in consumer prices (Geslin, 2019). Within EMCCA we recall, only Chad and the Central African Republic are landlocked as accessible only by land and air, road construction is, therefore, a capital imperative to be better integrated.

Furthermore, the weakness of road infrastructure is not the only difficulty. In EMCCA, there are also obstacles linked to electrical, health and digital infrastructures. These infrastructures cost much more to users in EMCCA countries. Electricity and road freight prices are on average three times higher in EMCCA countries than in other developing regions and dial-up Internet access costs six times more. (...) The small number of countries connected to the submarine cable and by can explain the high cost of ICT services in EMCCA the absence of competition between international gateways, even when the countries are connected (Sharmini \& Bernardin, 2013). 


\section{- The challenges related to the political instability}

The fragility of Central Africa is characterized by a volatile security environment and political instability. This situation results mainly from the outbreak of several multiform conflicts, notably for the control of natural resources or involving armed groups. These conflicts have been exacerbated by the inability of states to deal with insecurity and reconstruction, by a high level of poverty and a deficit in governance. In Central Africa, three countries are considered to be in fragile situations: The Central African Republic, the Democratic Republic of the Congo and Chad. The other four countries are perceived to be more resilient, although they also have pockets of fragility. It must be said that this political fragility of the Great Lakes region, the Lake Chad basin (especially in the north of Cameroon, west of Chad, southeast of Niger, northeast of Nigeria) and the Gulf of Guinea is strongly linked political dissension, weaknesses in the protection of human rights, limited transparency in the management of resources and electoral processes which continue to accentuate political fragility by creating social tensions. The extreme material poverty of the populations, the weakness in the governance of the soil and subsoil resources (hydrocarbons and minerals), the porosity of the borders as well as the failure of the public services of the States in certain parts of their territories are factors aggravating factors (BAD, 2019).

According to Geslin, political instability within EMCCA has led to several harmful consequences; namely the destruction or devaluation of physical capital (infrastructure, equipment), human capital as well as social capital which is based on trust. Also, a rise in unemployment and a loss of income, because they disrupt economic activities, $[\ldots]$ generate uncertainty, increase transaction costs and encourage capital flight, thus preventing producers from realizing their full productive potential. Also, it has the effect of shrinking the markets and encouraging the establishment of non-tariff barriers to regional trade through restrictions on the free movement of goods, people and capital. Finally, violent or armed instability induces a significant increase in security and defense spending, thus creating an effect of crowding out certain social spending and further undermining the budgetary balance (Geslin, 2019).

\section{- The challenges related to the Corruption}

As true as trade tends to become more and more palpable on the planet, corruption has become too because it is a phenomenon that has generally occurred in all international companies and sectors (police, transport, customs, taxes, politics, health and so on). The globally recognized agency the Transparency International gives us a good and broad definition. Generally speaking, as "the abuse of entrusted power for private gain", it can be classified as grand, petty and political, depending on the amounts of money lost and the sector where it occurs. Grand corruption consists of acts committed at a high level of government that distort policies or the central functioning of the state, enabling leaders to benefit at the expense of the public good. Petty corruption refers to everyday abuse of entrusted power by low- and mid-level public officials in their interactions with ordinary citizens, who often are trying to access basic goods or services in places 
like hospitals, schools, police departments, and other agencies. Political corruption is a manipulation of policies, institutions, and rules of procedure in the allocation of resources and financing by political decision-makers, who abuse their position to sustain their power, status and wealth ${ }^{1}$.

In Central Africa, particularly in the EMCCA zone, this phenomenon has gained momentum and gained momentum with the increase in poverty. Corruption has become commonplace and although efforts to reduce it have been recorded within the sub-region, the latter remains very marked. Table 2 below gives us an overview of the place occupied by these countries in terms of corruption over the past four years. The data collected comes from the 2019 Corruption Perception Index, produced by de Transparency International on 180 countries and territories while giving each a score of zero (very corrupt) to 100 (very clean).

Table 2 shows the evolution of the EMCCA countries in terms of corruption during four consecutive years. Gabon is the only country among the six, which displays figures above 30 , it is the proof of a will to recovery thanks to its anti-corruption campaign called "operation scorpion". The latter aims to consolidate Gabonese public finances. However, further efforts are expected more because overall the numbers are constant for the most part alarming for others. Indeed, Chad, Congo and Equatorial Guinea, in particular, have frightening figures. From 2016 to 2019, their average corruption index is very close to 0, especially 20.25, 19.75 and 16.33 respectively. These three EMCCA countries are among the top 10 most corrupt countries in Africa in $2020^{2}$.

Here are some difficulties with EMCCA. This list is not exhaustive because we preferred to cite the most obvious according to our expertise. In addition to the problems linked to the oil field, infrastructures (road, sanitary, electric and digital), political instability, and corruption are added problems linked to insecurity at the border, the unequal distribution of wealth, poor governance, high unemployment, a weak financial sector, dual membership of other Regional Economic

Table 2. Corruption perception index in EMCCA.

\begin{tabular}{cccccccc}
\hline Country & Rank/180 & 2019 & 2018 & 2017 & 2016 & Average Score & Score \\
\hline Gabon & 123 & 31 & 31 & 32 & 35 & 32.25 & Corrupted \\
Cameroon & 153 & 25 & 25 & 25 & 26 & 25.25 & Corrupted \\
CAR & 153 & 25 & 26 & 23 & 20 & 23.5 & Corrupted \\
Chad & 162 & 20 & 19 & 20 & 22 & 20.25 & Very corrupt \\
Congo & 165 & 19 & 19 & 21 & 20 & 19.75 & Very corrupt \\
Guinea Equatorial & 173 & 16 & 16 & $17^{3}$ & $/$ & 16.33 & Very corrupt \\
\hline
\end{tabular}

${ }^{1}$ https://www.transparency.org/what-is-corruption.

${ }^{2}$ https://afrique.le360.ma/autres-pays/societe/2020/01/25/29293-corruption-voici-les-10-least-and-m ost-corrupt-countries-in-africa-29293.

${ }^{3}$ https://www.transparency.org/cpi2019? utm_medium=email\&utm_campaign=Corruption\%20Perce ptions\%20Index\%202019\&utm_content=Corruption\%20Perceptions\%20Index\%202. 
Communities (RECs) and so on. Within this sub-regional community, the difficulties are legion. Fifty years after its creation, followed by various forms of restructuring and transformations, EMCCA remains an unprofitable integration organization. All these difficulties are inevitably intertwined, correlated, one concerning the other knowing that these states are all economically interdependent. In addition to tackling the underlying problems within their organization, EMCCA also has several prospective perspectives to take into account to achieve their economic development objective and among them, the cultural field through cultural tourism and cultural industries.

\section{Cultural Prospects for EMCCA Members}

\section{- Explore the field of Cultural Tourism}

The World Tourism Organization defines cultural tourism as the movement of people for essentially cultural reasons, such as study and cultural trips, art tours, travel to festivals and other cultural events, visits to sites and monuments, nature, folklore and art, and pilgrimages (Organisation Mondial du Tourisme, 2011). Central Africa, particularly the Economic and Monetary Community of Central Africa (EMCCA) zone, remains one of the places on the planet where there is still a very diverse flora and fauna and multiple natural resources. This region is characterized by a very dense ecosystem because the Congo basin occupies second place in the world in terms of natural and forestry resources.

In EMCCA, cultural tourism is still an anecdotal affair, due to the lack of substantial infrastructure, the scarcity of financial resources and the lack of adequate training. Without forgetting, the difficult access to cultural tourist places and sites due to the high cost of establishments and the advanced degradation of roads. A meeting was held in 2009, to finally set up mechanisms or policies to consider this sector, but 11 years later, nothing has been done yet. It must be said that tourism in Central Africa is struggling to take off. Faced with major security challenges, the region is having trouble attracting investors and tourists alike. Even Cameroon, which is relatively stable compared to its neighbors, receives around 1 million visitors each year. A low figure has given the country's high tourism potential, which is poorly exploited (Forum de l'Investissement Hôtelier Africain, 2019).

When should we have a "Safari" (tour or tourist trip undertaken by tourists to discover new places) in EMCCA? To become a recognized cultural tourist destination, the region of the member countries of the Economic and Monetary Community of Central Africa must ensure that it is perceived as a sufficiently captivating and attractive tourist destination, with adequate community hotel complexes, with favorable and harmonized prices. Now is the time to sit down and think about the economic impact it could have on these countries and their people. In the Economic and Monetary Community of Central, Gabon, and Cameroon ${ }^{4}$ ${ }^{4}$ https://netafrique.net/les-3-destinations-les-plus-interessantes-en-afrique-centrale/. 
are among the most interesting destinations in Central Africa in 2017. This is due to the presence of the 13 national parks of Gabon of which that of Lopé is registered in the world heritage of Unesco and the 4 tourist regions of Cameroon: (the great North Adamaoua, North and Extreme-North), the South (Center, East, and part of the South), the Littoral (Littoral, part of the South and South-West), the West (West and North-West). Without forgetting that the other countries, also have precious and particular tourist particularities such as the Republic of Congo with its vestiges historic slaves and national parks; the Central African Republic with its Manovo-Gounda St Floris National Park, listed as World Heritage by UNESCO. It is one of the richest reserves in Africa ${ }^{5}$, and so on. EMCCA is a gold mine for cultural tourism. The tourist activity can grow, become a sector of activity likely to boost the economic, social and sustainable development of a given territory, become a major economic sector which, together with health and education, can contribute to the multifaceted development of societies, but on condition that its potentialities are exploited and managed rationally in the perspective of sustainable tourism and development (Meirama, 2016). Therefore, the EMCCA member states should commit in:

1) Encourage the development of this sector of activity thanks to the effective contribution of the local populations concerned.

2) Promote cultural tourism through the development of cultural tourism complexes presenting regional cultures such as works of art, artistic troupes, traditional culinary art, and music and so on. At least everything that emerges from the tangible and intangible cultural heritage of these countries with the same cultural origins, namely that of the Bantu people 6 . This was the reason being of the International Center for Bantu Civilizations created in 1983 to set up the largest computerized cultural database in Africa. And, on this same basis, build a body of research and scientific and cultural pan-Bantu productions well up to the double quest of being-in-the-world and of being-together summoned by such a requirement, in pride and dignity reaffirmed, at the heart of a community of united destiny ${ }^{7}$. The initiative was laudable and very welcome, but today this center is considered a "white elephant" because no one works there anymore and it has become a shelter for the homeless. More than 10 billion CFA francs (15 million euros) have been swallowed up by this oversized project, weighed down by managerial mistakes and by the cessation of payment of member states' contributions (Georges, 2016). Real awareness is necessary to reverse this economic decline in EMCCA and this project deserves to be reconsidered by inter-regional mutual assistance and the action of other regional organizations.

3) Establish alliances with other regional organizations and another private https://www.alibabuy.com/guide-touristique/centrafrique.html.

${ }^{6}$ This word means "people" or "human". The term Bantu does not specifically refer to an ethnic group or a particular language, but a group of more than 400 ethnic groups who speak the Bantu languages and live in Central Africa, East Africa and Southern Africa. All EMCCA countries are from it except for Chad. https://www.hauniversity.org/fr/Bantu.shtml.

${ }^{7}$ https://www.cicibabantu.org/e-ciciba/oquer. 
sector to develop training programs, skills sharing, develop several spaces for cultural tourism cooperation, and thus widen the list of desired actors to give better visibility to EMCCA intraregional cultural tourism.

\section{- Explore the field of Cultural Industries}

This expression was used for the first time by the fathers of the Frankfurt School of Sociology, the German philosophers Theodor Adorno and Max Horkheimer in their work The Dialecte of the reason published in 1944, to stigmatize the influence of industrial modernity as a source of domination over the production of artistic works. According to their analysis, the technology of the cultural industry has only resulted in standardization and mass production, sacrificing everything that made the difference between the logic of the work and that of the social system. That is to say, all works produced in series lost what constituted their authenticity when subjected to technical reproduction. However, it was towards the end of the 1970s that the concept of the cultural industry was to be evaluated in the plural while becoming more specific. This expression now refers to industries that produce and distribute cultural goods and services because they have become a vast field whose definitions can be diverse. According to Jean-Pierre Warnier, in his book the mondialisation of culture, they are defined as industrial activities that produce and market speeches, sounds, images, arts, and any other ability or habit acquired by man as a member of society. For UNESCO, it is a sector that agrees to combine the creation, production, and marketing of goods and services whose particularity lies in the intangibility of their content of a cultural nature, generally protected by rights of the author. And according to Doctor Kanel in his work entitled, The Development of Cultural Industries in Gabon, Cultural Industries are the cultural products of a work of creation subject to the laws of supply and demand and which obey the phases of creation, production, and dissemination that make possible its marketing. Thus, because of the specific nature of these products, the cultural industries are a composite wealth provider, because they alone represent 7.3\% of world GDP and 3\% in developing countries according to the World Bank. Also, among the most dominant cultural industries, we find the publishing, audiovisual (radio, television, and film), and music sectors.

Regional economic integration proves to be the important channel for the development of regional cultural industries for Africa and the EMCCA countries in particular. Francisco Ayi d'Almeida believes that the imbalance between the potential of countries that are major suppliers of cultural products and that of African countries means that the latter must give themselves the means to support the development and distribution of their production. They are also responsible for ensuring that the activities of cultural enterprises are carried out under viable economic conditions to enable them to face strong competition in their markets and internationally. The development of African cultural industries could be articulated in the audiovisual sectors (music, image, live performance), everyday objects and writing necessary for the development of human capital and the expression of identities. They have the advantage of having high 
demand linked to high expectations from the public and have a high capacity for integration. Only an economic space like the regional space is conducive to consolidating and developing their capacity to meet demand (Francisco, 2006).

Besides, cultural industries are sources of wealth with certain economic benefits. They support regional integration insofar as certain citizens of other states consume the products of one country. The book, music, film, audiovisual, festival, fashion, craft, and paint industries have gained in promotion of pluralism (Waziri, 2007). Currently, poorly diversified trade relations make the various EMCCA economies very dependent on each other. The observation that we make comparisons in the evolution of the industrialized countries is fundamentally similar; they became aware of their cultural assets to develop their economy. With the arrival of Bollywood for example, we see rhythmic dances steeped in tradition, charm, and belief. A little further, we see Nollywood for Nigeria and the Hollywood giant of the United States, not to mention the New Information Technologies and Communication (NTIC), which are constantly developing. Culture is the best ambassador to make his country known to the world (Sabrina, 2019). The realities and living conditions are not the same, but EMCCA has the advantage of being from the same people, the Bantu. Therefore, the diversity and cultural richness of its integration organization are one of the tracks of economic development to follow to get this region out of its state of deep economic sleep. This is advantageous insofar as each of the political leaders should focus on how to get out of this economic crisis effectively instead of tackling it individually. The diversity and cultural richness of the Economic and Monetary Community of Central Africa is one of the tracks of economic development to follow to get this region out of its state of deep economic sleep. Although for the moment, the EMCCA countries mainly export raw materials, anything that is not favorable to its industrial take-off, we think that the cultural industries could be a useful sector to explore to allow them to diversify their exchanges and to share their experience in specific areas. They should unite to:

1) Organize their different respective cultural institutions and give a common guideline. This would imply putting in place common cultural policies aimed at guiding the cultural integration of populations in effective and practical ways.

2) Take up industrial challenges and costs firstly in terms of production in terms of both quantity and quality, then in terms of regional distribution and marketing in all sectors of activity in the cultural industries. It must be said, that no large-scale production project can succeed without the prior agreement of a distributor decided to market it, because it gives financiers the guarantee that the work would be well exploited (Kanel, 2012). The latter is even more important knowing well that in Africa and EMCCA in particular, there are very few public or private structures, which could intervene concretely in the distribution and the marketing of cultural products. The pooling of cultural assets would be a potential asset in the emergence of Made in EMCCA cultural products.

3) Have a legal basis on which these initiatives will be based.

4) Create the Regional Society of Cultural Industries of the Economic and 
Monetary Community of Central Africa (RSCI-EMCCA), whose organization chart could be presented as follows (Figure 1).

The Regional Society of Cultural Industries of the Economic and Monetary Community of Central Africa (RSCI-EMCCA) would be placed under the supervision of the ministries of cultural affairs of each State or would simply be annexed to a department within EMCCA. It would aim to promote and strengthen the establishment and development of cultural enterprises in member countries while ensuring regulations and strict compliance with the measures taken jointly. Work together to finally provide cultural products "Made in $E M C C A$ ". It would ensure the proper functioning of the most active fields of cinema, publishing, radio, television, crafts, the arts, and live performances. The company would be administered by a board of directors, managed by a director-general elected by vote and by deputy directors assigned to manage for each cultural department. A support fund called the Community Cultural Industries Support Fund (CCISF) will be attached to the general management then to that of logistics, technical and NICs, which will ensure that it has the human resources, equipment, and materials necessary to the proper functioning of each sector. Besides, funding for the Fund could come not only from the stakeholders but also from other regional bodies, from several other private or public sources and even from international organizations.

Growing globalization requires EMCCA member countries, in particular, to be competitive and to have a benefit on their products. It is, therefore, necessary, if not essential, to be culturally well rooted to trade with other countries. Cultural Tourism and Cultural Industries are sectors that will never run out. These fields in the future will require our countries to be equipped to respond to the never-ending challenges that are emerging on the international scene. These two sectors, providers of wealth, also meet the needs of supply and demand while promoting the creation of multifaceted and multisector jobs such as human resources manager, technical staff, sound and lighting engineers, publishers, distributors, whether direct or indirect via platforms, stage director, hotel managers, designers, decorators, sanitation management, accounting manager, IT

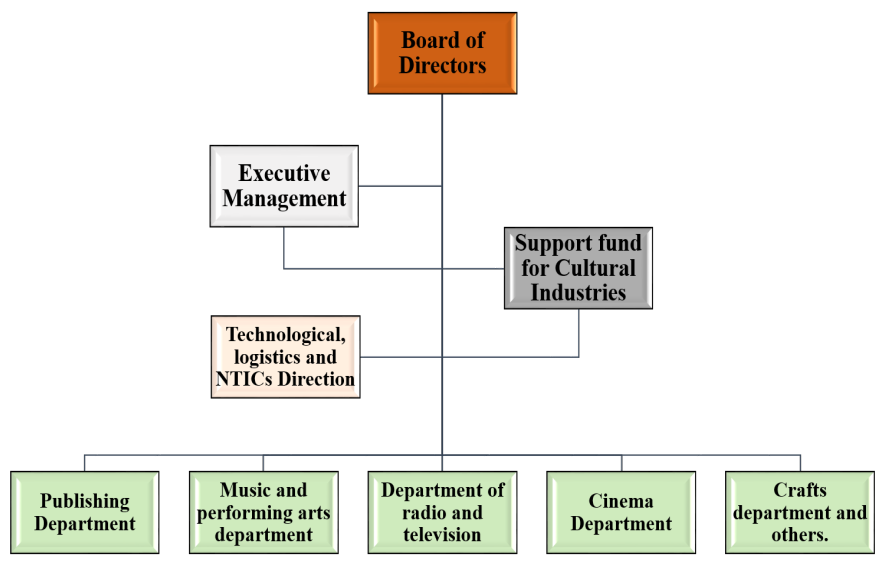

Figure 1. Organization chart of RSCI-EMCCA. 
specialists, technicians, and so on. These two plans combined would make it possible to reduce the high unemployment rate in EMCCA. Indeed, in 2019, Gabon had the highest unemployment rate with $19.6 \%$, followed by the Republic of Congo 10.4\%, Equatorial Guinea 9.2\%, the Central African Republic 6.5\%, Cameroon 3, 3\% and Chad 2.3\% ${ }^{8}$. Although the latter two countries have low percentages does not mean that their economies create good jobs. Few people find suitable work in EMCCA and many prefer to try their luck in activities in the informal sector, living even day today to support themselves.

\section{Conclusion}

Africa can be seen as a risk. Africa is seen by many as a risk, but for us, Africa can be a great opportunity. If we all join hands, if we act today, today, not tomorrow because it will be late. If we act within the framework of a broad consensus to exercise our leadership and establish the agenda for Africa, Konare, 2002.

Central Africa and especially EMCCA is a region prone to many difficulties. In addition to being the continent's least integrated inter-regional economic integration, evils such as corruption, poor governance, political instability, looting of wealth, poverty, lack of infrastructure and others characterize it. This region today enjoys all the derogatory denominations because about fifty years after its existence, one always speaks about the same difficulties. However, this part of the continent is full of a multitude of natural, energy, mining and above all cultural riches. It is time for this paradox to end a region of immense wealth and incredible realities of life. We need to get up and transform the natural, economic and cultural benefits that we have into a driving force that creates income and well-being for all (Sabrina, 2019). To do this, the field of culture via cultural tourism and cultural industries must be explored in the community. While the cultural sector is an important sector for the economic development of African regional integrations, regional integration represents a solid and essential basis for the development of these cultural enterprises. One cannot be dissociated from the other, just as the culture cannot be dissociated from the economy, which constitutes its framework.

The economic gap accumulated by EMCCA is enormous, but not impossible to fill if everyone wants to leave their interests aside for the search for regional stability, the development of the respective economies and the well-being of the populations. This research must inevitably go through a change of mind so that the voluntarism of the States and the awakening of massive consciences, come out of concrete solutions stimulating the rise of economies. Thus, it would be necessary to make use of the natural assets that the cultural domain provides benefit from the positive spinoffs of globalization. Made in EMCCA will only be possible if the states not only strive to redefine cultural policies more concerned with their community needs but also to invest intensely and qualitatively in the 
training of young elites. Everyone, including EMCCA, can be a winner in the globalization of trade if they have the right assets and the right cooperation partners at their side.

The data collected throughout this article, allowed us to inquire about the place occupied by the cultural field within said organization. This wealth-providing sector remains unexplored, knowing that no new economic order can take place without a new cultural order. However, aware that this article has certainly not been able to address all cultural aspects, we hope to have modestly contributed our stone to the future economic development of the Economic and Monetary Community of Central Africa. The cultural field is no longer a negligible sector if not now a provider of wealth and a creator of jobs. The fact is that alone, these countries do not manage to have better economic profitability and their respective cultural field remains neglected or even overlooked. However, EMCCA member countries are economically interdependent. Economic and cultural unity is more than ever vital for this organization of sub-regional integration to become a profitable cause for all.

\section{Acknowledgements}

We especially thank Professor Wei Hong of Central China Normal University for this valuable advice. Also, thanks to Dienguila Kionga D., Freddy Mitsoune and our beloved ones for their help, love and multiform support.

\section{Conflicts of Interest}

The authors declare no conflicts of interest regarding the publication of this paper.

\section{References}

BAD (2019). Perspectives économiques en Afrique central. https://www.afdb.org/sites/default/files/documents/publications/per_2019-afrique_cen trale.pdf

CEMAC (2019). Sommet Extraordinaire des Chefs d'Etats de la Communauté Economique et Monétaire de l'Afrique Centrale.

Direction générale des relations internationales et de la stratégie (2015). Impact de la baisse du prix du pétrole sur les pays producteurs d'Afrique équatoriale (Cameroun, Congo-Brazzaville, Gabon et Guinée équatoriale).

Edouard, G. T. (2004). Droit Matériel et Intégration Sous-régionale en Afrique centrale (Contribution à l'étude des mutations récentes du marché interieur et du droit de la concurrence CEMAC).

Emilie, L., \& Serge, J. E. (2014). Les Pays de la CEMAC convergent-ils? https://www.insee.fr/fr/statistiques/fichier/2120944/stec108b.pdf

Etienne, K. (2012). Transport routier et effectivité de l'intégration régionale dans l'espace CEMAC : Enjeux et contraintes pour le développement durable du Congo.

Forum de l'Investissement Hôtelier Africain (2019). I'Afrique centrale, un gisement touristique inexploité.

https://www.pouvoirsafrique.com/2019/02/07/fiha-2019-lafrique-centrale-un-gisement -touristique-inexploite/ 
Francisco, A. A. (2006). L'enjeu de l'intégration régionale pour les industries culturelles africaines. Africultures No. 69. https://doi.org/10.3917/afcul.069.0149

François, B. (1968). L'Union des Etats de l'Afrique Centrale (pp. 167-177). https://www.persee.fr/doc/afdi_0066-3085_1968_num_14_1_1484 https://doi.org/10.3406/afdi.1968.1484

Georges, D. (2016). Bantous:la quête des origines. https://www.jeuneafrique.com/mag/316823/culture/bantous-quete-origines/

Geslin, M. M. M. (2019). Les principaux obstacles aux échanges commerciaux intra sousrégionaux en Afrique Centrale: Cas de la Communauté Économique et Monétaire de l'Afrique Centrale (CEMAC).

Jacqueline, D. (2005). Le développement de l'Afrique centrale dans une perspective d'avenir. Afrique contemporaine No. 215. https://doi.org/10.3917/afco.215.0029

Kanel, E. N. (2012). Le Développement des Industries Culturelles au Gabon. Paris, l'Harmattan.

Meirama, G. M. (2016). Ressources patrimoniales et perspectives touristiques dans l'EstCameroun: Potentialités et limites actuelles. https://journals.openedtion.org/etudescaribeennes/9453

Nagou, M. Y. (2012). Apport de la culture dans l'accélération du processus d'intégration régionale: Cas de l'Afrique de l'Ouest.

Niambi, N. T. (2018). Bilateral Cooperation between China and Congo-Brazzaville: The Other Side of the Ledger. https://doi.org/10.4236/ojps.2018.83016

Niambi, T. N. (2019). France and China in Central Africa: From Competition to Cooperation, China.

Organisation Mondial du Tourisme (2011). Le Tourisme culturel. http://www.culturalamontreal.com/19/Le_tourisme_en_bref.htm\#160

Plan d'action sur les industries culturelles et creatives (2004). https://au.int/sites/default/files/pages/32901-file-au_plan_daction_french.pdf

Sabrina, L. N. (2019). Cultural Impact within the Bilateral Cooperation between China and Gabon. Open Journal of Political Science, 9, 599-609. https://doi.org/10.4236/ojps.2019.94036

Sharmini, C., \& Bernardin, A. (2013). Le déficit d'infrastructures dans les pays de la CEMAC: Problèmes et solutions possibles. https://www.elibrary.imf.org/view/IMF071/12595-9781475584233/12595978147558423 3/ch04.xml?language $=$ es\&redirect $=$ true

Waziri, M. (2007). Les états-nations face à l'intégration régionale en Afrique de l'ouest: Le Cas du Niger. 